\title{
Detection of virulence-associated genes in Brucella melitensis biovar 3, the prevalent field strain in different animal species in Egypt
}

\author{
Mahmoud E.R. Hamdy* and Hoda M. Zaki \\ Department of Brucellosis Research, Animal Health Research Institute, Cairo, Egypt
}

\begin{abstract}
The current study involved detection of three virulence genes (bvfA, virB, ure) by PCR in 52 isolates of Brucella melitensis biovar 3, recovered from different animal species (28 sheep, 10 goats, 9 cattle and 5 buffaloes). Of the 52 B. melitensis strains; 48 (92.3\%) isolates carried bvfA genes, 51 (98.1\%) isolates had virB genes and 50 (96.2\%) isolates were positive for ure genes. The distribution of the virulence genes is not affected by crossing the original host barriers of the animal species, as the three virulence factors (bvfA, virB and ure) detected in 28 B. melitensis isolates obtained from ovine species in a ratio of 26/28 (92.9\%), 27/28 (96.4\%) and 28/28 (100\%), respectively. While 10 isolates originating from goats revealed a ratio of 10/10 (100\%), 10/10 (100\%) and 9/10 (90\%) to the same order of virulence genes. Nearly, similar results of virulence genes detection were obtained in B. melitensis obtained from bovine (8/9, 9/9 and 8/9) and Buffalos (4/5,5/5 and 5/5), respectively. The high prevalence of virulence-associated genes among the $B$. melitensis isolates detected from different animal species in Egypt indicates a potential virulence of this bacterium.
\end{abstract}

Keywords: Brucella melitensis biovar 3, Egypt, PCR, Virulence genes.

\section{Introduction}

Brucellosis is primarily a disease of animals that infects many domestic terrestrial mammals as well as some of the aquatic species. The pathogen transmitted from animals to humans by the ingestion of infected food products, direct contact with an infected animal or inhalation of aerosols (Schutze and Jacobs, 2011). The genus Brucella has traditionally been classified according to animal host preference into 6 species; $B$. melitensis (goats and sheep), $B$. abortus (cattle), $B$. suis (pigs), $B . \quad$ neotomae (desert $\quad$ woodrats), $B$. ovis (rams), B. canis (dogs), (Alton et al., 1988; Godfroid et al., 2011). Recently $B$. ceti and $B$. pinnipedialis, have been isolated from cetacean and pinniped species, respectively (Foster et al., 2007). B. microti was isolated from the common vole (Al Dahouk et al., 2012). Finally, B. inopinata, was isolated from a human breast implant (Scholz et al., 2010).

Although, Brucellosis is common in many developing countries, B. melitensis infection is considered the predominant strain in Egypt and Near East countries, not only in sheep and goats (preference host) but also in cattle, buffaloes, and camels as well as in humans (Refai, 2002; Wareth et al., 2014a).

Brucellosis is a major public health problem in Egypt especially in the Nile Delta region (Samaha et al., 2009). The clinical manifestations of brucellosis in infected humans are not pathognomonic and usually misdiagnosed with many other infectious and noninfectious diseases (Franco et al., 2007). B. melitensis, based on to its high pathogenicity and virulence, is categorized by the World Health Organization (WHO) as a risk group III. Contrary to some traditional views, B. melitensis remains fully virulent for human beings after infecting cattle (Hamdy and Amin, 2002; Wareth et al., 2014b).

Genetic and immunological evidence indicates that all members of the genus Brucella are closely related. Nevertheless, it has many virulence factors causing sever pathogenicity (Gandara et al., 2001). Differences in virulence have been observed in members of the genus Brucella, and the levels of virulence order shown in guinea-pigs seems to be similar to that in humans whereas, B. melitensis scored the high level of virulence followed by $B$. suis and $B$. abortus (Smith and Ficht, 1990).

It has been proved that mice infected with $B$. melitensis had a strong inflammatory response and prolonged splenomegaly compared with those induced by other Brucella strains (Crawford et al., 1996). Brucella employs a number of mechanisms for avoiding bactericidal responses inside macrophages. Unlike rough strains, smooth brucella organisms engulfed by macrophages, proved to play a role in suppressing macrophage apoptosis subsequently they have the ability to survive for longer periods inside macrophages (Pei et al., 2006).

Among the different gene elements responsible for virulence in Brucellae the bvfA, ure, and VirB are the most common factors. Brucella virulence factor A 
( $b v f A$ ) has been defined as being responsible for Brucella survival in the host cells. BvfA size is $11 \mathrm{kDa}$ that unique to the genus Brucella and suggests it may play a role in the establishment of the intracellular niche.

Although $b v f A$ was essential for Brucella virulence in both in vitro and in vivo, its particular role in virulence is still unrevealed (Lavigne et al., 2005). VirB proteins that form the type IV secretion system (T4SS) that play a role in intracellular replication are considered as one of the Brucella virulence factors (Delrue et al., 2005). One of the remarkable and important virulence factors in Brucella is the urease (ure). Urease is a virulence factor that plays a role in the resistance of Brucella to low $\mathrm{pH}$ conditions, both in vivo and in vitro (Sangari $e t$ al., 2010).

The detection of virulence genes in B. melitensis biovar 3 , the predominant field strain in different animal species in Egypt has not been addressed. Therefore, the objective of this study is to detect and determine the presence and distribution of the common virulencerelated genes in $B$. melitensis field strains isolated from sheep, goats, cattle and buffaloes in Egypt.

\section{Bacterial strains}

\section{Materials and Methods}

A total of 52 Brucella isolates recovered from clinical specimens (Table-1) of different animal species (28 sheep, 10 goats, 9 cattle and 5 isolates from buffaloes) within a period of 2 years (2015-2017). All isolates were identified and biotyped according to the methods adopted elsewhere (Alton et al., 1988; OIE, 2016). The identification of Brucella culture on the genus level was carried out based on colonial morphology, microscopic examination with modified Ziehl-Neelsen stain, and reaction with standard brucella positive and negative sera.

The smoothness of Brucella colonies was assessed based on colonial morphology, acriflavine test and staining the colonies with crystal violet. While biotyping of Brucella isolates was based on $\mathrm{CO}_{2}$ requirement for primary isolation, production of $\mathrm{H}_{2} \mathrm{~S}$ : growth in presence of thionin $(1 / 25.000,1: 50.000$, $1: 100.000)$ and basic fuchsin (1/50.000 and 1:100.000), urease production, reaction with mono-specific sera (A and $\mathrm{M}$ ), catalase reaction and the usage of the following phages; Tblisi (Tb), Iz, and Weybridge - Wb (Alton et al., 1988; OIE, 2016). All 52 isolates proved to be $B$. melitensis biovar 3 .

\section{Template preparation}

Each Brucella isolate cultured on Tryptic soy agar plate without addition of antibiotic was incubated at $37 \mathrm{C}$ for 72 hours under $10 \% \mathrm{CO} 2$ tension. Brucella colonies were picked and suspended in $500 \mu \mathrm{l}$ of distilled water. After mixing, the suspension was boiled for $5 \mathrm{~min}$, and $300 \mu \mathrm{l}$ of the supernatant was collected after spinning at $14,000 \mathrm{rpm}$ for $10 \mathrm{~min}$.

\section{DNA extraction}

DNA extraction from samples was performed using the QIAamp DNA Mini kit (Qiagen, Germany, GmbH) with modifications from the manufacturer's recommendations. Briefly, $200 \mu 1$ of the sample suspension was incubated with $10 \mu \mathrm{l}$ of proteinase $\mathrm{K}$ and $200 \mu \mathrm{l}$ of lysis buffer at $56^{\circ} \mathrm{C}$ for $10 \mathrm{~min}$. After incubation, $200 \mu 1$ of $100 \%$ ethanol was added to the lysate. The sample was then washed and centrifuged following the manufacturer's recommendations. Nucleic acid was eluted with $100 \mu 1$ of elution buffer provided in the kit. The DNA concentration was determined with spectrophotometer (O'Callaghan et al., 1999).

\section{Oligonucleotide Primers}

Primers used were supplied from biobasic (Canada) and are listed in table (2).

\section{PCR amplification}

Primers were utilized in a $25-\mu 1$ reaction containing $12.5 \mu 1$ of Emerald-Amp Max PCR Master Mix (Takara, Japan), $1 \mu \mathrm{l}$ of each primer of $20 \mathrm{pmol}$ concentration, $5.5 \mu \mathrm{l}$ of water, and $5 \mu 1$ of DNA template. The reaction was performed in an Applied Bio-system (ABI) 2720 thermal cycler.

\section{Analysis of the PCR Products}

The products of uniplex PCR were separated by electrophoresis on $1 \%$ agarose gel (Applichem, Germany, GmbH) in 1x TBE buffer at room temperature using gradients of $5 \mathrm{~V} / \mathrm{cm}$. For gel analysis, $20 \mu 1$ of the products were loaded in each gel slot. A gel pilot 100 bp plus DNA ladder (Qiagen, Gmbh, Germany), gene ruler 100 bp ladder (Fermentas, Germany) and DNA ladder H3 RTU (Genedirex, Taiwan) were used to determine the fragment sizes. The amplified products in agarose gel were visualized by ultraviolet transilluminator after gel staining with ethidium bromide stain. The gel was photographed by a gel documentation system (Alpha Innotech, Biometra). Sterile DNA-free water used as a control negative and B. melitensis biovar 3 reference strain (ATCC No., 23458) was used as control positive. Internal quality control samples were employed in the PCR process to ensure and exclude DNA contamination.

\section{Results and Discussion}

The pathogenicity and virulence of Brucella species is mostly attributed to their ability to survive intracellualry and to overcome unfavorable environmental conditions. Brucella has adapted to elude the reaction of the immune system, survive intracellular trafficking, and resist the low oxygen conditions encountered inside macrophages (Saeedzadeh et al., 2012).

In the current study, DNA was successfully extracted from all $52 \mathrm{~B}$. melitensis isolates obtained from different animal species. 
Table 1. distribution of Brucella isolates according to animal species and origin of samples.

\begin{tabular}{|c|c|c|c|c|c|c|}
\hline \multirow{2}{*}{ Animal Species } & \multirow{2}{*}{ Aborted foetus } & \multirow{2}{*}{ L.N. } & \multirow{2}{*}{ Milk } & \multicolumn{2}{|c|}{ Organs tissues } & \multirow{2}{*}{ Total } \\
\hline & & & & Spleen & Liver & \\
\hline Sheep & 5 & 13 & 5 & 3 & 2 & 28 \\
\hline Goats & 3 & 4 & 2 & 1 & & 10 \\
\hline Cattle & 2 & 1 & 4 & 1 & 1 & 9 \\
\hline Buffaloes & 1 & 2 & 2 & & & 5 \\
\hline Total & 11 & 20 & 13 & 5 & 3 & 52 \\
\hline
\end{tabular}

Table 2. Primers sequences, target genes, amplicon sizes and cycling conditions for conventional PCR.

\begin{tabular}{llcccccc}
\hline \multirow{2}{*}{$\begin{array}{l}\text { Target } \\
\text { gene }\end{array}$} & Primers sequences & $\begin{array}{c}\text { Amplified } \\
\text { segment } \\
\text { byfA }\end{array}$ & $\begin{array}{c}\text { Primary } \\
\text { denaturation }\end{array}$ & $\begin{array}{c}\text { Secondary } \\
\text { denaturation }\end{array}$ & Annealing & Extension & Final \\
extension
\end{tabular}

As expected the $b v f \mathrm{~A}$, virB and ure genes assays with PCR produced amplicons of 1282, 881 and $2100 \mathrm{bp}$ respectively (Fig. 1, 2 and 3). Of the 52 B. melitensis strains; $48(92.3 \%)$ isolates were positive for $b v f A$ gene, $51(98.1 \%)$ isolates carried virB gene and in $50(96.2 \%)$ isolates ure gene was detected. It is noteworthy to find that irrespective of the animal species from which $B$. melitensis was isolated, the distribution of virulence genes among the isolates was not affected by crossing the animal species host barrier.

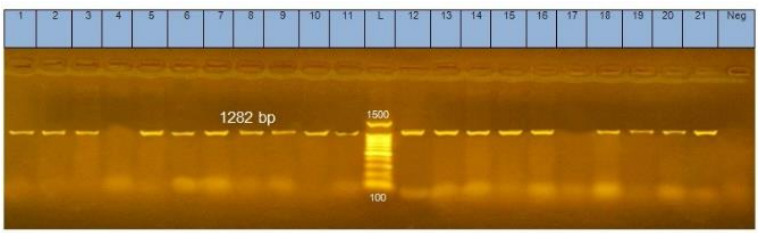

Fig. 1. Agarose gel electrophoresis image of virulence factor gene $b v f A$ in B. melitensis isolates, where L; Marker (100bp), Negative; left lane, positive control; lane 21. All samples shown positive PCR product for the $b v f A$ virulence gene except samples numbers 4 and 17 they were negative.

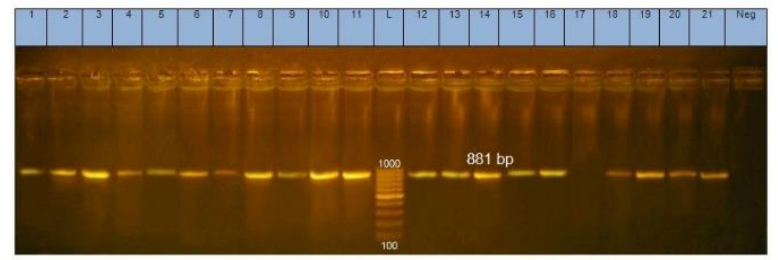

Fig. 2. Agarose gel electrophoresis image of virulence factor gene virB in B. melitensis isolates, where L; Marker (100bp), Negative control; left lane; positive control lane 21. All samples shown positive PCR product for the virB virulence gene except sample number 17.

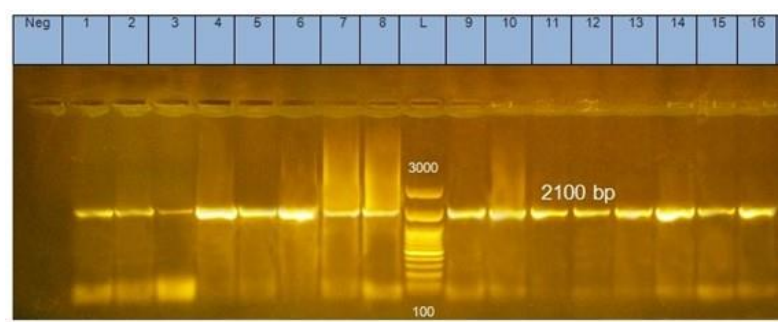

Fig. 3. Agarose gel electrophoresis image of virulence factor gene ure in B. melitensis isolates, where L; Marker (100bp), Negative control; right lane; positive control lane 1. All samples shown positive PCR product for the ure virulence gene.

The same levels of distribution of the three virulence genes was observed in all B. melitensis isolates, under test, regardless of the animal species. As the three virulence factors viz. $b v f A, v i r B$ and ure were detected in $28 \mathrm{~B}$. melitensis isolates originated from ovine species in a ratio of 26/28 (92.9\%), 27/28 (96.4\%) and $28 / 28(100 \%)$, respectively. While the ratio for three virulence genes namely $b v f A$, virB and ure in 10 isolates originating from goats revealed a ratio of $10 / 10$ (100\%), $10 / 10 \quad(100 \%)$ and $9 / 10 \quad(90 \%)$, respectively. Nearly, similar results of virulence genes detection were obtained in $B$. melitensis obtained from bovine (8/9, 9/9 and 8/9) and Buffalos (4/5, 5/5 and $5 / 5$ ), respectively (Table 3 ).

In this investigation, we found that $92.3 \%$ of $B$. melitensis isolates had $b v f \mathrm{~A}$ genes which is similar to other studies, where Naseri et al. (2016) detected the $b v f \mathrm{~A}$ gene in $93 \%$ of $B$. melitensis strains isolated from human blood in Iran. 
Table 3. Detection of virulence genes in B. melitensis isolated from different organs of different animal species.

\begin{tabular}{|c|c|c|c|c|c|}
\hline \multirow{2}{*}{ Sample } & \multirow{2}{*}{$\begin{array}{l}\text { Animal } \\
\text { Species }\end{array}$} & \multirow{2}{*}{ Organ } & \multicolumn{3}{|c|}{ Results } \\
\hline & & & $b v f A$ & $\operatorname{vir} B$ & ure \\
\hline 1 & \multirow{28}{*}{$\frac{2}{\frac{0}{4}}$} & L.N. & + & + & + \\
\hline 2 & & L.N. & + & + & + \\
\hline 3 & & L.N. & + & + & + \\
\hline 4 & & L.N. & - & + & + \\
\hline 5 & & L.N. & + & + & + \\
\hline 6 & & L.N. & + & + & + \\
\hline 7 & & L.N. & + & + & + \\
\hline 8 & & L.N. & + & + & + \\
\hline 9 & & L.N. & + & + & + \\
\hline 10 & & L.N. & + & + & + \\
\hline 11 & & L.N. & + & + & + \\
\hline 12 & & L.N. & + & + & + \\
\hline 13 & & L.N. & + & + & + \\
\hline 14 & & Milk & + & + & + \\
\hline 15 & & Milk & + & + & + \\
\hline 16 & & Milk & + & + & + \\
\hline 17 & & Milk & - & - & + \\
\hline 18 & & Milk & + & + & + \\
\hline 19 & & Spleen & + & + & + \\
\hline 20 & & Spleen & + & + & + \\
\hline 21 & & Spleen & + & + & + \\
\hline 22 & & liver & + & + & + \\
\hline 23 & & liver & + & + & + \\
\hline 24 & & A.F. & + & + & + \\
\hline 25 & & A.F. & + & + & + \\
\hline 26 & & A.F. & + & + & + \\
\hline 27 & & A.F. & + & + & + \\
\hline 28 & & A.F. & + & + & + \\
\hline 29 & \multirow{10}{*}{ 苞 } & L.N. & + & + & + \\
\hline 30 & & L.N. & + & + & + \\
\hline 31 & & L.N. & + & + & + \\
\hline 32 & & L.N. & + & + & + \\
\hline 33 & & Milk & + & + & - \\
\hline 34 & & Milk & + & + & + \\
\hline 35 & & Spleen & + & + & + \\
\hline 36 & & A.F. & + & + & + \\
\hline 37 & & A.F. & + & + & + \\
\hline 38 & & A.F. & + & + & + \\
\hline 39 & \multirow{9}{*}{ 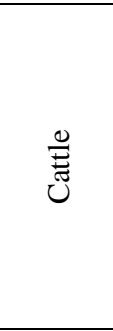 } & L.N. & + & + & + \\
\hline 40 & & Milk & + & + & + \\
\hline 41 & & Milk & - & + & + \\
\hline 42 & & Milk & + & + & + \\
\hline 43 & & Milk & + & + & - \\
\hline 44 & & Spleen & + & + & + \\
\hline 45 & & Liver & + & + & + \\
\hline 46 & & A.F. & + & + & + \\
\hline 47 & & A.F. & + & + & + \\
\hline 48 & \multirow{5}{*}{ 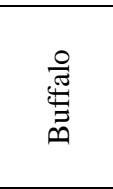 } & L.N. & + & + & + \\
\hline 49 & & L.N. & + & + & + \\
\hline 50 & & Milk & - & + & + \\
\hline 51 & & Milk & + & + & + \\
\hline 52 & & A.F. & + & + & + \\
\hline \multicolumn{2}{|c|}{ Total } & 52 & 48 & 51 & 50 \\
\hline \multicolumn{3}{|c|}{$\%$} & $92.3 \%$ & $98.1 \%$ & $96.2 \%$ \\
\hline
\end{tabular}

(A.F.): Aborted foetus; (L.N.): Lymph node.
On the other hand, only $78.5 \%$ of $B$. melitensis strains originating from aborted goats, in Iran, having $b v f \mathrm{~A}$ in their genomes (Derakhshandeh et al., 2013).

The current study show that $98.1 \%$ of the 52 local $B$. melitensis isolates had virB genes. This is in accordance with other studies, where virB genes detected in $100 \%$ $B$. melitensis strains isolated from human patients (Naseri et al., 2016), and disagree with the results reported by Derakhshandeh et al. (2013) who found virB genes in only $73.8 \%$ of 42 B. melitensis strains isolated from goats. This discrepancies may indicate that $B$. melitensis field strains prevailing in Egypt are more virulent than the strains of $B$. melitensis isolated from caprines in Iran. As, it was emphasized that the T4SS of Brucella encoded by the virB operon is a major virulence factor (Delrue et al., 2005).

In spite of their well-established immune-evasive behavior, Brucella spp. do rely on an important virulence factor for intracellular survival, the type IV secretion system (T4SS) encoded by the genes virB1virB12 (den Hartigh et al., 2008). Viable Brucella evades macrophage killing through VirB-dependent sustained interactions with the endoplasmic reticulum (ER). The role of virB operon for the intra-cellular survival of Brucellae may have two possible passways, either the virB operon is necessary to reach a competent intracellular replication niche or the $\operatorname{vir} B$ operon is required for replication once the intracellular replication niche has been established (Saeedzadeh et al., 2012).

The results of the present study showed that most $B$. melitensis isolates have virulence factor gene ure $(96.2 \%)$ in their genome. The ure genes has been hypothesized to play a role in the pathogenesis of disease. Other studies showed that about (100\%) of $B$. melitensis strains originating from human sources having ure genes in their genome (Naseri et al., 2016) while the ure genes detected in 42 B. melitensis strains isolated from caprine species were approximately $88.09 \%$ (Derakhshandeh et al., 2013).

The virulence of Brucella isolates was reported to be in relation with the rate of urease activity (Seleem $e t$ al., 2008). The microbial ureases that play a role in virulence is based on the action of multi-subunit enzymes that hydrolyze urea to form carbon dioxide and ammonia. Thus the hydrolysis of urea releases ammonium that turns the surrounding environment to the alkaline shift and facilitates intracellular survival in acidic environments.

The role of bacterial ureases in infectious disease has been recently reviewed. It was investigated that most Brucella species show a strong urease activity, derived from ure 1 but not from ure2, and this activity is responsible for the ability of Brucella to survive acidic environment, particularly through the transmission of the infection through ingestion or gastric route 
(Bandara et al., 2007). This finding is substantiated by the fact that $B$. ovis is not able to infect the host by the gastrointestinal route, a fact that has been linked to lack of urease activity in B. ovis (Tsolis et al., 2009). This may refer to the role of urease activity as it is responsible for the pathogenies and virulence Brucella strains.

Isolated B. melitensis biovar 3 incorporated in this study showed fast urease activity within 30 to 75 minutes from incubation on Christensen's solid medium (Data not shown). However, it was stated that reference $B$. melitensis strains were considered slow urea splitters but an increasing percentage of recently isolated cultures are urease positive within one hour and many are indistinguishable from B. suis in the rate of urease activity (Alton et al., 1988).

These findings may explain why $B$. melitensis induces greater acute infectivity in Fisher-344 rats, whereas $B$. suis causes chronic infectivity; and urease activity has no influence on Brucella infection using an intraperitoneal (IP) route (Bandara et al., 2013). These findings are in harmony with results obtained in the current study where $96.2 \%$ of $B$. melitensis had ure genes that indicating the high virulence of the local $B$. melitensis strains isolated from different animal species in Egypt.

\section{Conclusion}

A high proportion of $B$. melitensis strains recovered from clinical cases from animals were positive for the virulence genes viz. $b v f A(92.3 \%)$ virB $(98.1 \%)$, and ure $(96.2 \%)$. The high prevalence of virulenceassociated genes among the $B$. melitensis isolates detected from different animal species in Egypt indicates a potential virulence of this bacterium. Thereby this study offers a clear insight into the high virulence and pathogenic characteristics of $B$. melitensis biovar 3, predominating in the Egyptian region, and may be helpful to veterinary officials and public health authorities to set national campaigns for the control and eradication of this hazard.

However, further studies were needed to unveil the role of selected virulence genes and the factors responsible for expression of these genes in eliciting the massive inflammatory response that results in abortion and to elucidate the infectious cycle of this pathogen.

\section{Conflict of interest}

The authors declare that there is no conflict of interests.

\section{References}

Al Dahouk, S., Hofer, E., Tomaso, H., Vergnaud, G., Le Fle` che, P., Cloeckaert, A., Koylass, M. S., Whatmore, A.M., Nöckler, K. and Scholz, H.C. 2012. Intraspecies biodiversity of the genetically homologous species Brucella microti. Appl. Environ. Microbiol. 78, 1534-1543.
Alton, G.G., Jones, L.M., Angus, R.D. and Verger, J.M. 1988. Techniques for the brucellosis laboratory. $1^{\text {st }}$ ed. INRA. Paris.

Bandara, A.B., Contreras, A., Contreras-Rodriguez, A., Martins, A.M., Dobrean, V., Poff-Reichow, S., Rajasekaran, P., Sriranganathan, N., Schurig, G.G. and Boyle, S.M. 2007. Brucella suis urease encoded by ure1 but not ure 2 is necessary for intestinal infection of BALB/c mice. BMC Microbiol. 2007, 7:57. doi: 10.1186/1471-2180-7-57.

Bandara, A.B., Boyle, S.M., Contreras-Rodriguez, A., Martins, A.M., Prasad, R. and Reilly, C.M. 2013. Brucella melitensis Differs from B. suis in Growth and Urease Activity In-Vitro, and Infectivity in Fisher-344 Rats In-Vivo. Adv. Infect. Dis. 3, 60-62.

Crawford, R.M., VanDeverg, L., Ywan, L., Hadfieled, T.L., Warren, R.I. and Hoover, D.L. 1996. Detection of pure attenuates Brucella melitensis infection in mice. Infect. Immun. 64, 2188-2192.

Delrue, R.M., Deschamps, C., Leonard, S., Nijskens, C., Danese, I., Schaus, J.M., Bonnot, S., Ferooz, J., Tibor, A., De Bolle, X. and Letesson, J.J. 2005. A quorum sensing regulator controls expression of both the type IV secretion system and the flagellar apparatus of Brucella melitensis. Cell Microbiol. 7, 1151-1161.

den Hartigh, A.B., Rolan, H.G., de Jong, M.F. and Tsolis, R.M. 2008. VirB3-VirB6 and VirB8VirB11, but not VirB7, are essential for mediating persistence Brucella in the reticuloendothelial system. J. Bacteriol. 190, 4427-4436.

Derakhshandeh, A., Firouzi, R. and Goudarztalejerd, A. 2013. Detection of virulence genes (bvfA, virB and ure) in Brucella melitensis isolated from aborted fetuses of sheep and goats. Iran J. Microbiol. 5(4), 402-405.

Foster, G., Osterman, B.S., Godfroid, J., Jacques, I. and Cloeckaert, A. 2007. Brucella ceti sp. nov. and Brucella pinnipedialis sp. nov. for Brucella strains with cetaceans and seals as their preferred hosts. Int. J. Syst. Evol. Microbiol. 57(Pt11), 2688-2693.

Franco, M.P., Mulder, M., Gilman, R.H. and Smits, H.L. 2007. Human brucellosis. Lancet Infect. Dis. 7(12), 775-786.

Gandara, B., Merino, A.L., Rogel, M.A. and MartinezRomero, E. 2001. Limited genetic diversity of Brucella spp. J. Clin. Microbiol. 39, 235-240.

Godfroid, J., Scholz, H., Barbier, T., Nicolas, C., Wattiau, P., Fretin, D., Whatmore, A.M., Cloeckaert, A., Blasco, J.M., Moriyon, I., Saegerman, C., Muma, J.B., Al Dahouk, S., Neubauer, H. and Letesson, J.J. 2011. Brucellosis at the animal/ecosystem/human interface at the beginning of the 21 st century. Prev. Vet. Med. 102, 118-131. 
Hamdy, M.E.R. and Amin, A.S. 2002. Detection of Brucella Species in the Milk of Infected Cattle, Sheep, Goats and Camels by PCR. Vet. J. 163, 299305.

Lavigne, J.P., Patey, G., Sangari, F.J., Bourg, G., Ramuz, M., O'Callaghan, D. and MichauxCharachon, S. 2005. Identification of a new virulence factor, BvfA, in Brucella suis. Infect. Immun. 73, 5524-5529.

Naseri, Z., Alikhani, M.Y., Hashemi, S.H., Kamarehei, F. and Arabestani, M.R. 2016. Prevalence of the Most Common Virulence- Associated Genes among Brucella Melitensis Isolates from Human Blood Cultures in Hamadan Province, West of Iran. Iran J. Med. Sci. 41(5), 422-429.

O'Callaghan, D., Cazevieille, C., Allardet-Servent, A., Boschiroli, M.L., Bourg, G., Foulongne, V., Frutos, P., Kulakov, Y. and Ramuz, M. 1999. A homologue of the Agrobacterium tumefaciens VirB and Bordetella pertussis Ptl type IV secretion systems is essential for intracellular survival of Brucella suis. Mol. Microbiol. 33, 1210-1220.

OIE. 2016. Brucellosis (Brucella abortus, B. melitensis and B. suis), Chapter 2.1.4. Manual of Diagnostic Tests and Vaccines for Terrestrial Animals. Office International des Epizooties, Paris.

Pei, J., Turse, J.E., Wu, Q. and Fitch, T.A. 2006. Brucella abortus rough mutants induce macrophage oncosis that requires bacterial protein synthesis and direct interaction with the macrophage. Infect. Immun. 74, 2667-2675.

Refai, M. 2002. Incidence and control of brucellosis in the Near East region. Vet. Microbiol. 90, 81-110.

Saeedzadeh, A., Sharifiyazdi, H. and Firouzi, R. 2012. Molecular. characterization of Brucella melitensis Rev.1 strain in aborted sheep and goats in Iran. Comp. Clin. Pathol. 22, 409-412.

Samaha, H., Mohamed, T.R., Khoudair, R.M. and Ashour, H.M. 2009. Serodiagnosis of brucellosis in cattle and humans in Egypt. Immunobiology 214, 223-226
Sangari, F.J., Cayón, A.M., Seoane, A. and GarcíaLobo, J.M. 2010. Brucella abortus ure2 region contains anacid-activated urea transporter and a nickel transport system. BMC Microbiol. 10:107. doi: 10.1186/1471-2180-10-107.

Scholz, H.C., Nockler, K., Gollner, C., Bahn, P., Vergnaud, G., Tomaso, H., Al Dahouk, S., Kampfer, P., Cloec-kaert, A., Maquart, M.M., Zygmunt, S., Whatmore, A.M., Pfeffer, M., Huber, B., Busse H.J. and De, B.K. 2010. Brucella inopinata sp. nov., Isolated from a Breast Implant Infection. Int. J. Syst. Evol. Microbiol. 60, 801-808.

Schutze, G.E. and Jacobs, R.F. 2011. Brucella in Kliegman Behrman jenson, Nelson Text Book of Pediatrics $19^{\text {th }}$ edition.Chapter 199; Philadelphia , Pennsylvania.

Seleem, M.N., Stephen, M.B. and Nammalwar, S. 2008. Brucella: A pathogen without classic virulence genes. Vet. Microbiol. 129, 1-14.

Smith, D.S. and Ficht, T.A. 1990. Pathogenesis of Brucella. Microbiology 17, 209-230.

Tsolis, R.M., Seshadri, R., Santos, R.L., Sangari, F.J., Lobo, J.M., de Jong, M.F., Ren, Q., Myers, G., Brinkac, L.M., Nelson, W.C., Deboy, R.T., Angiuoli, S., Khouri, H., Dimitrov, G., Robinson, J.R., Mulligan, S., Walker, R.L., Elzer, P.E., Hassan, K.A. and Paulsen, I.T. 2009. Genome degradation in Brucella ovis corresponds with narrowing of its host range and tissue tropism. PLoS One 4(5):e5519. doi: 10.1371/journal.pone.0005519.

Wareth, G., Hikal, A., Refai, M., Melzer, F., Roesler, U. and Neubauer, H. 2014a. Review: Animal brucellosis in Egypt. J. Infect. Dev. Ctries. 8(11), 1365-1373.

Wareth, G., Melzer, F., Elschner, M.C., F.M., Neubauer, H. and Roesler, U. 2014b. Detection of Brucella melitensis in bovine milk and milk products from apparently healthy animals in Egypt by real-time PCR. J. Infect. Dev. Ctries. 8(10), 1339-1343. 